\title{
Effectiveness of Positive Deviance Approach to Promote Exclusive Breastfeeding Practice: A Cluster Randomized Controlled Trial
}

\author{
Yibeltal Siraneh (1D) \\ Mirkuzie Woldie (iD ${ }^{2}$ \\ Zewdie Birhanu (D) ${ }^{3}$ \\ 'Department of Health Policy and \\ Management, Faculty of Public Health, \\ Jimma University, Jimma, Ethiopia; \\ ${ }^{2}$ Department of Global Health and \\ Population, Harvard T.H. Chan School of \\ Public Health, Boston, MA, USA; \\ ${ }^{3}$ Department of Health, Behavior and \\ Society, Faculty of Public Health, Jimma \\ University, Jimma, Ethiopia
}

Background: Suboptimal breastfeeding (BF) contributes to a significant number of infant deaths. A positive deviance approach (PDA) was not studied in Ethiopia, whether it improve exclusive breastfeeding (EBF) practice. Therefore, we determined the effectiveness of positive deviant approached intervention in increasing the proportion of EBF practice.

Methods: A cluster-randomized controlled trial was employed in Jimma town from February 01 to September 30, 2018. Six randomly selected clusters (kebeles) were randomized into two arms. Then, 260 mothers who met the eligibility criteria were enrolled in either the intervention or control arm depending on where they lived. Women in the intervention group received counseling and social support in addition to the usual service to promote EBF, from women identified and trained as positive deviants in their community, while those in the control groups received the usual community-based services from urban health extension professionals. Data on primary and secondary outcome variables were collected at three points, and statistical difference was estimated using Chi- $X^{2}$ or Fisher exact test. The net effect of the intervention was calculated. The magnitude of the intervention effect was estimated using the relative risk. For all statistical tests, $95 \%$ CI with a P-value of $<0.05$ was used.

Results: The overall response rate at the endline was $98.8 \%$. Exclusive BF was significantly different between the groups at mid and end points, while no difference at baseline. A higher proportion of mothers in the intervention group reported EBF compared to the control group at mid and end-line. The rate of EBF increased by $18.5 \%(\mathrm{P}=0.01)$ in the intervention group while $0.2 \%$ in the counterparts, with a net effect of $+18.2 \%$. The probability of practicing EBF was significantly higher for the intervention group compared to the control group. At baseline, the relative risk of avoiding EBF (RR:1.112) was similar among the two groups. However, at follow-up, mothers in the intervention group were 2 times more likely to practice EBF (RR: 2.294) compared to those in the control group.

Conclusion and Recommendation: The PD approach is an effective intervention to promote EBF and also positively affected frequency and duration of BF. Therefore, we recommend the promotion and use of positive deviance approach as a strategy to improve EBF practice in urban settings.

Trial Registration Number: Clinical trial PACTR201805003379263, 23 May 2018.

Keywords: effectiveness, positive deviance, breastfeeding, exclusive, randomized controlled trial

\section{Background}

Exclusive breast feeding (EBF) is the situation where the infant has received only breast milk except for supplements, vaccines or medicines for the first 6 months. 
Breastfeeding (BF) is one of the most important postpartum care to the newborn to thrive and survive. ${ }^{1,2}$ Breast milk provides all nutritional and fluid needs in the first 6 months and is a perfect combination of different nutrients. It is the best and cost-effective intervention to reduce infant morbidity and mortality from infectious diseases that disproportionately affect children under five in developing countries. In addition, appropriate BF is critical for optimal growth, brain development, and cognition. ${ }^{3}$ Mothers, therefore, are encouraged to feed breast milk only for the first 6 months, ${ }^{4}$ and continue BF together with proper complementary feeding up to 2 years of age. ${ }^{5}$

Poor feeding in infanthood is associated with negative health outcomes. ${ }^{6}$ Infants suffer from high rates of acute malnutrition, which is primarily attributed to poor breast and other feeding practices. ${ }^{7}$ Suboptimal BF contributes $45 \%$ of neonatal deaths, due to infectious causes, in developing countries. ${ }^{8}$ Positively speaking, optimal BF has the potential to prevent 1.4 million infant deaths worldwide. The reduction of high neonatal mortality is an urgent priority in many countries of the world. For example, Nepal reduced under-five mortality due to the implementation of community-based child health program provided by local community health volunteers. Studies suggest that home visits can reduce newborn deaths by $30 \%$ depending on the type of approach selected. ${ }^{9}$

Despite the existence of different interventions, the global burden of neonatal deaths is still unacceptably high. From 2015 onward, for 15 years, with further implementation of proven health interventions, it is anticipated that the infectious causes of death will decline more quickly. However, because of the high number of births, sub-Saharan Africa's share of global child deaths is expected to increase from $49.6 \%$ to $59.8 \%$ by $2030 .{ }^{10-12}$ Most of these deaths happen during the first month after birth, which could be due to conditions preventable through practicing EBF. ${ }^{13}$ For this critical time, WHO and UNICEF recommended different packages for training and supporting community health workers (CHWs) caring for newborns through five home-based visits. ${ }^{4,13}$ In addition to the general care and counseling, supporting the mother to initiate timely and sustained EBF is also expected care to be provided. However, its implementation is questionable in Ethiopia. ${ }^{11}$

In Ethiopia, poor BF practice is reported disproportionately high in urban settings. Due to these poor feeding practices, stunting, wasting and underweight were reported significantly. ${ }^{14}$ The fact that significant proportions of children were not fed according to the WHO recommended practices. ${ }^{1,14}$ To address this, the child survival and development strategy was designed nationally. This aims at accelerating and scale-up of evidence-based highimpact, safe and cost-effective interventions which is EBF for the first 6 months. ${ }^{15}$ For this reason, as a component of essential newborn care, a guideline was adopted to promote BF practices at the community level. ${ }^{16}$ However, still suboptimal $\mathrm{BF}$ contributes $24 \%$ of the total infant death annually. ${ }^{12}$ Community health programs expected to address such basic health issues since the period of the primary health care movement. Following this, the Health Extension Program (HEP) has been implementing at rural and urban settings since 2003 and 2009 with essential health promotive and preventive packages. ${ }^{17}$

A different paradigm from the usual, with a new strategy for health promotion, is the positive deviance approach. This approach is focusing on the idea that solutions to problems already exist within the community, often practiced by positive deviants who engage effectively, although uncommon, healthy behaviors. Once identified, these practices are shared with community members in different ways. ${ }^{18}$ This approach assumed that (a) Communities already have the solutions, and best experts to solve their problems, (b) Communities are selforganized and have the social assets to solve an agreedupon problem, (c) Collective intelligence and know-how is not concentrated in external experts but it is distributed throughout the community, (d) Sustainability as the cornerstone of the approach, and (e) it is easier to change behavior by practicing rather than knowing about it. ${ }^{18,19}$ The most efficient way to improve health is to use locally available, indigenous, sustainable, and effective approaches after rigorous testing. ${ }^{19}$ When a generic approach is introduced for local problem solving, its effectiveness always depends on contextual factors. This means the concept of PDA is not one size fit for all rather it needs to start from scratch to test it anywhere. This approach requires discovering uncommon positive cases that fulfill criteria pre-set examples. ${ }^{20,21}$ It also needs context-based well-defined communication strategy and psycho-social support to improve the complex nature of $\mathrm{BF}$ behavior change. $^{22}$

Therefore, identifying strategic approach and implementing in context is demanding in Ethiopia. Accordingly, of the identified and prioritized 34 interventions in the Ethiopian Child Survival Strategy, 17 are to improve neonatal survival. ${ }^{12}$ However, most deaths took 
place during the first month of birth due to conditions that can be prevented with effective interventions such as EBF. The first day is considered as the most challenging time for the mother to breastfeed and for the newborn to survive. ${ }^{13}$ For this critical time, the community-based packages should be delivered at home. ${ }^{12,13}$ However, we questioned its effectiveness in Ethiopia since deaths were continuedstill 59/1000 children died under the age of one, of which $90 \%$ deaths were preventable by practicing $\mathrm{EBF}^{23}$ and poor performance reported. ${ }^{23,24}$ Nationally, $59 \%$ of infants exclusively BF till 6 months, which declined from $71 \%$ in the first month and the median duration of EBF was 3.1 months. Although BF rates are improving (from $49 \%$ in 2005 to $59 \%$ in 2019), the practice is suboptimal to decrease infant deaths, ${ }^{25}$ because of neonatal mortality ratio went from bad to worse. ${ }^{25}$ Although guiding principles to implement the strategy were set, the achievement so far remains poor and indicates inadequate preparation. Hence, promoting the practice of EBF by implementing a new approach could be one of the strategies of primary health care and rigorously testing as we did in this study. An approach that is tested in context, and practical is demanding to promote EBF practice. ${ }^{26}$

In Jimma town, 16,000 mothers completed the model household training package-placing it below average nationally. Training packages are 16 modules related with health promotion and prevention aspects of different community health problems. Each module has content, objectives, and mode of delivery to be given for 60 hours. The household with a trained woman called "a model household"-a family that implemented all health services extension packages concerning its family with the support and close supervision of health extension professionals. The expected changes to be a model household include visible changes in behavior. Evidence showed that model families were not actively participating in the implementation of the packages. ${ }^{24,27}$ Low $(4.3 \%)$ practice of home visit by HEPs or HDA leaders, poor social support, negative subjective norms about EBF and its challenges at weaning period, career or job-related challenges to practice $\mathrm{EBF}$, increasing intention toward industrial products, ${ }^{24,28}$ and gap on predisposing, enabling and reinforcing factors of EBF were the common challenges. ${ }^{29}$ A low proportion of EBF-33.2\% in the past ${ }^{30}$ and $32.31 \%$ currently at baseline of this study as compared to the national-59\% and rural level-67\% were reported, ${ }^{8,25}$ besides the national guidelines discourage pre-lacteal feeding and promote EBF practice ${ }^{12,15,31}$ Therefore, since there was no evidence related, we implemented a trial intervention using PDA which aimed to determine its effectiveness in increasing the proportion of EBF practice.

\section{Methods and Participants Study Area and Period}

This community-based trial study was conducted in Jimma town, Ethiopia, from February01 to September30, 2018. Jimma is 1 of 12 administrative towns in the region of Oromia. The town has 17 kebeles (the smallest administrative units in Ethiopia) with an estimated population of 192,000 people. The health system includes two government hospitals, one private hospital, four health centers, and 17 working sites (same to health posts) for UHEPs. The ratio of health extension professionals to households and population are 1:745 and 1:3254, respectively, which is less than the expected national standard of $1: 500$ and 1:1500, respectively. In thesecond quarter of 2017, the local health officials reported that there were 1260 pregnant women in the third trimester in Jimma town. ${ }^{24}$

\section{Study Design/Approach}

Experimental design with a cluster randomized controlled single-blind, parallel-group, two-arm trial with a 1:1 allocation ratio was employed. This design was feasible to implement in the community setting, where units of randomization were clusters. Since it was behavioral intervention (informational counseling and social support) considering clusters could minimize information cross-contamination. The data collectors were blinded.

A participatory action design/approach was used to implement the intervention. Participatory design is research on design and clarifying the process. "Research for design" refers to research about design processes, how they are carried out and what are their results; "research by design" refers to making an artifact where the thinking is embodied in the artifact, and "research through design" refers to research into materials and forms for exploring possibilities. Although participatory design includes all three types of research, in this study; "research for design" was applied. Therefore, integrated participatory action research (PAR) with RCT study was applied to be called an implementation study. ${ }^{32}$ 


\section{Source and Study Population}

All women in their third trimester of pregnancy, living in Jimma town were the source population. The study populations were pregnant women in their third trimester (36 weeks of gestational age), living in selected kebeles/clusters of Jimma town.

\section{Eligibility Criteria}

Pregnant women who were in the third trimester of pregnancy (36 weeks of gestational age), living in the selected cluster, and who gave birth in the last 5 years, and who had no known medical/physical problem that prevents BF practice, capable of giving informed consent and willing to be home visited by PDs, supervisors and data collectors and no plan of moving away for at least a year were included in the study. Thirty-six, 37, and 38-40 weeks of gestational age were the times used for enrollment, baseline data collection, and for the first home visit of the intervention group, respectively. We preferred to include women who gave birth in the last 5 years to have the baseline information about BF practice, and related variables before the intervention. This is because of illogicality to start the intervention after delivery since exclusive BF practice is breached mostly within 1-3 days of postdelivery. After enrollment at 36 weeks, the death of a mother and/or baby at birth, or stillbirth, preterm birth before baseline data collected, clinical complications related to hospitalization for more than a week, anatomical malformation that prevents $\mathrm{BF}$, and lost first visit at 38-40 weeks were exclusion criteria. When this case happened till the first week of birth, other eligible pregnant women were replaced.

\section{Sample Size Determination}

The sample size was calculated using Designing Clinical and translational Research software Version UCSF-DCR-4 in comparing proportion with a dichotomous outcome. We estimated the sample size using the Chi-squared statistic based on the following assumptions: 95\% confidence level, $80 \%$ power, number of subjects in the intervention to control group ratio $1: 1$, the proportion of mothers in intervention and control group practicing $\mathrm{EBF}=33.3 \%\left(\mathrm{P}_{0}\right.$ =proportion of EBF in control groups) with AOR of 2.1. ${ }^{30}$ $\mathrm{P}_{1}$ was the proportion of outcome in the intervention group, which changes in the practice of EBF from the assumed baseline; it is expected to increase the level of EBF practice by a minimum of $15 \%$ detectable differences. Hence, $\mathrm{P}_{1}=48.3 \%$. This yields a sample of 118 in each group. By adding 10\% expected nonresponse rate to each sample size and multiplied by two arms, the total sample size became 260 . Therefore, the number of mothers in the intervention and control group was 130 each.

\section{Sampling Technique, Randomization, and Enrollment}

Out of 17 clusters (kebeles) found in Jimma town, 12 nonadjacent clusters were selected considering the remaining as buffer zones. Then, $50 \%$ of these ( 6 clusters) were randomly selected using a lottery method. Clusters were the unit of randomization for the trial, while mothers within the respective clusters were units of analysis. The six clusters were randomly allocated to the intervention and control arms using a simple randomization technique. First, each cluster was represented using numbers $1-6$, and then a random number generator using SPSS version 21 was applied to get half the number of the total. Then, a lottery method was applied to decide the intervention and control group. Based on this, the first three clusters (Ginjo-Gudiru, Awetu-mendera, Mendera-Kochi) were randomized as intervention sites, and the remaining (Hermata-Mentina, Mentina, and Bosa-Kito) as control site.

A statistician, who was blinded to study groups and not participated in this study, randomized the clusters and allocated into two arms. Study participants were not concealed since they certainly knew their group. However, data collectors were not informed of the allocation, not being residents in any of the clusters and not part of the trial implementers.

Ahead of randomization, all pregnant women in the selected clusters were identified from family folder-logbook at health post, followed by rapid community survey with the assistance of health extension professionals. However, recruitment was started after clusters had been randomized. A total of 310 third trimester pregnant women who lived in the six clusters were identified. The group sample was allocated proportional to each cluster's number of third trimester pregnant women. Then, recruitment and enrollment continued till the proportionally allocated sample size was attained in each cluster of the respective arms (130/130) keeping the eligibility criteria. Forty-five women were excluded for not meeting the criteria, and five refused to participate. The remaining eligible 260 mothers were enrolled to either the intervention or control 
group depending on where they lived. Each enrolled woman was traced using their address and phone number to reach them at their home (Figure 1).

\section{Study Variables}

The primary outcome variables were EBF practice and change in rates of $\mathrm{BF}$ indicators, while secondary outcome variables were knowledge on EBF, attitude and subjective norm toward EBF, and self-efficacy to practice EBF. The explanatory variable (intervention variable) was counseling and social support by PDs, whereas the baseline characteristics were socio-demographic variables (age, educational status, ethnicity, religion, marital status, occupational status, monthly income), obstetric and previous support-related variables (parity, mode of delivery, sex preference, received home visit from HEPs, received home visit from model mothers, receiving support from relevant others), and BFrelated variables (place of delivery, source of information about EBF, previous experience of BF-for the last child, intention to breastfeed for the upcoming baby). Operational definitions and measurements were annexed (Supplementary File:Annex-I).

\section{Intervention Approach: Positive Deviance Approach}

The positive deviance approach was used to guide the intervention through a participatory design. In the study area, there are mothers whose uncommon but successful behaviors enable them to find better solutions while feeding breast milk only for the first 6 months. Participatory approach was followed to iteratively construct the emerging design and elicits the qualitative results as cointerpreted by the researchers and the participants who used or implemented the design.

The method of a participatory design ensured whether the participants' interpretations are taken into account in the intervention. Participants' cointerpretation of the research was not to confirm but

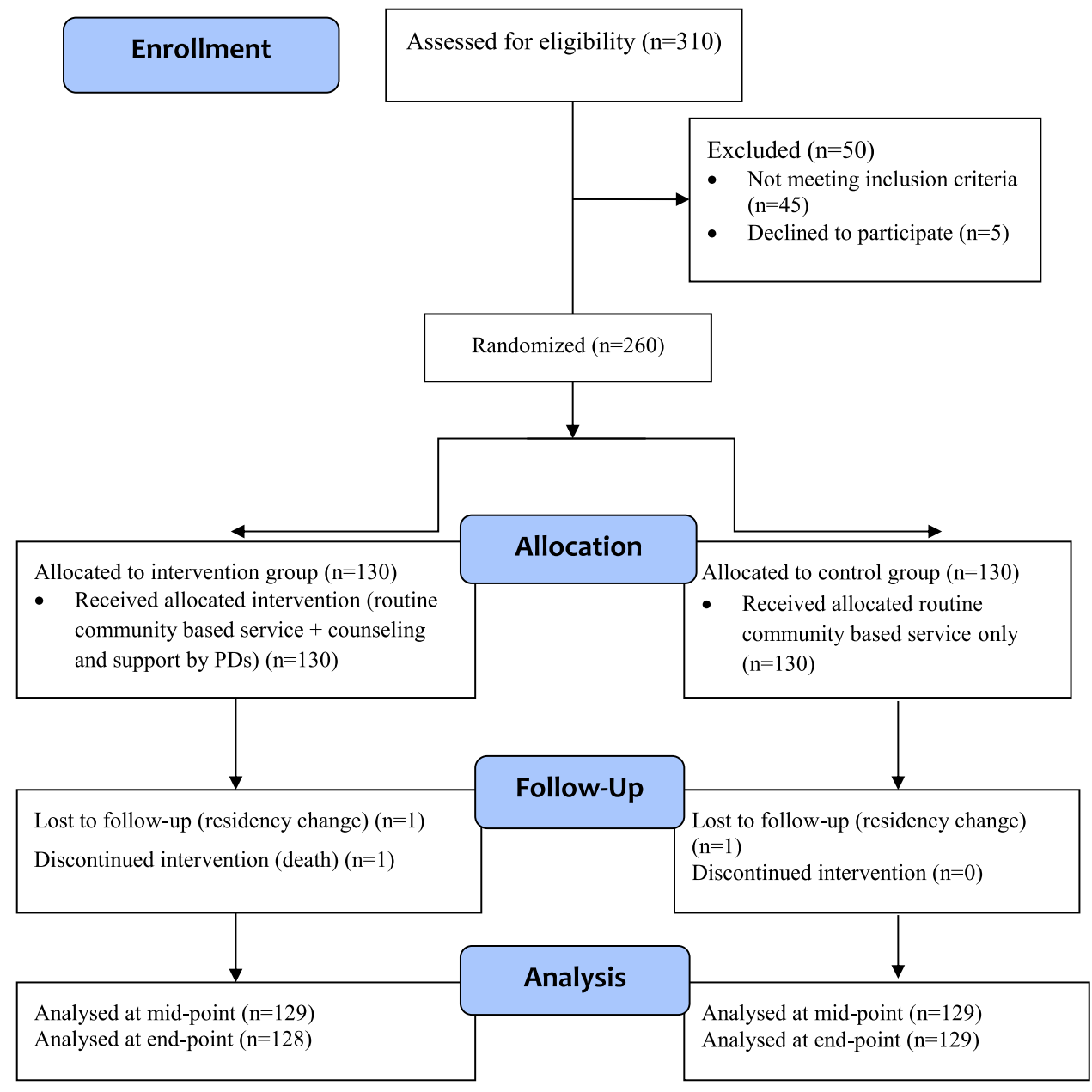

Figure I Trial flow chart using CONSORT 2010, intervention study, Jimma town, 2021. 
also considered as an essential part of the process. These aspects were productively and ethically examined through partnerships including the tacit, invisible aspects of mothers' activity. The researcher and PDs cooperatively designed artifacts, workflow, and work environments; and argued iteratively so that they developed and refined their understanding of the activities. This design helped the researchers to understand the tacit and implicit knowledge rather than explicit, holistic rather than bounded and systematized; it is what mothers know without being able to articulate. The mothers' knowledge is too layered to be fully articulated but have experience. They better communicate through actions than words. We understood these through the positive deviance inquiry as knowledge is a condition of a certain context. This means the PD approach helped to get the lived experience from mothers and to use them for the intervention practically although mothers might fail to articulate in words. This participatory design helped the researchers to find a common "language" with implementers, and to capture diverse information on how to implement the intervention.

In the process, future users or implementers of the solutions were involved in the design of those solutions through shared knowledge that would improve the design. The design process facilitated user participation throughout emphasizing mutual learning (problem setting and solving) and co-construction of the new solution in its real context.

The project team, health extension professionals, and invited volunteer women identified the positive deviants and practices using series of six steps: defining the problem of EBF (problem clearly stated), exploring the presence of PD individuals (confirmed their presence and selected using five criteria), discovering uncommon practices/behaviors (clearly described and discovered), designing the program (designed with clear objectives, activities and outcome), planning for monitoring and evaluation (developed framework and agreed), and planning for scale-up (how to scale-up and sustain discussed). The detailed reports for these steps were annexed (Supplementary File: Annex-II).

\section{Intervention Activities}

\section{For Intervention Group}

Comprehensive and personalized counseling and social support intervention packages provided for mothers allocated to the intervention group at their home by trained positive deviants to promote EBF practice using their preferred local languages (Afan Oromo and Amharic). PDs provided face-to-face informational counseling and psychosocial support. Thirteen trained positive deviants were assigned to visit 10 mothers each, 6 times on the predetermined schedule. Positive deviants were community volunteers but we certified them in recognition of their active role and incentivized with minimum acceptable refreshment cost that permitted by the Jimma Institute of Health-Institutional Review Board (JIH-IRB) which was $0.5 \mathrm{USD} /$ visit. This means $5 \mathrm{USD}$ per 10 home visits at each round (total rounds-6). The counseling and support protocol assumed to take 45 minutes at each visit based on the following points (Table 1).

1. Informational counseling: This constitutes individual counseling to share best-lived experiences and updated with training content adapted ${ }^{33}$ on exclusive $\mathrm{BF}$ and any relevant to the newborn care. They also recommended practicing Kangaroo Mother Care (KMC) if needed to maintain the infant's body temperature, and to stimulate BF. Low-birth-weight and preterm neonates who were indicated by the birth attendant should be put on Kangaroo mother care. This means giving breast milk while placing the baby in between the two breasts because that initiates the newborn to suck strongly and survive. Summary of intervention activities, schedule, training modules and main contents (Table 1), and co-created BF messages were supplemented (Supplementary File: AnnexIII).

The PDs were trained on WHO/UNICEF "Breastfeeding Counselling guideline" with different modalities including classroom sessions for providing theoretical aspects of breastfeeding, counseling and communication; practical sessions on counseling skills (listening and learning skills, confidence and support skills) and simulation. Lectures, demonstrations/simulation, and work in smaller groups with discussion and role-plays were training methods used. Then, the content of modules for the intervention was developed (co-created) in consultation with the PDs to be used in the follow-up visits.

2. Psychosocial support and verification of their understanding concerning the continuum of infant care including EBF. This includes a plan on how to care 
Table I Summary of Implementation Activities to Improve EBF Practice, Jimma Town, 2018

\begin{tabular}{|c|c|c|c|c|}
\hline S.No. & $\begin{array}{l}\text { Implementation } \\
\text { Activities }\end{array}$ & $\begin{array}{l}\text { Responsible } \\
\text { Body }\end{array}$ & Place of Field Work & Strategy/Activities \\
\hline $\mathrm{I}$. & Enrolling eligible mothers & $\begin{array}{l}\text { Project team } \\
\text { and UHEPs }\end{array}$ & $\begin{array}{l}\text { Facility based and } \\
\text { community based - At } \\
\text { health post/site and Home } \\
\text { to home }\end{array}$ & $\begin{array}{l}\text { Listing from family folder with identifiers and making } \\
\text { rapid community survey }\end{array}$ \\
\hline 2. & $\begin{array}{l}\text { Capacity building training } \\
\text { for WHDA leaders and } \\
\text { HEPs on PD approach }\end{array}$ & Project team & $\begin{array}{l}\text { Facility based - At Health } \\
\text { post/site }\end{array}$ & $\begin{array}{l}\text { All HEPs and WHDA leaders were communicated } \\
\text { formaly and training on how to proceed with PDA } \\
\text { principles and the way forward for this intervention } \\
\text { study }\end{array}$ \\
\hline 3. & $\begin{array}{l}\text { Identifying positive deviants } \\
\text { and training them }\end{array}$ & $\begin{array}{l}\text { Project team, } \\
\text { WHDA } \\
\text { leaders and } \\
\text { HEPs }\end{array}$ & $\begin{array}{l}\text { Facility based - At selected } \\
\text { Kebeles/Health posts }\end{array}$ & $\begin{array}{l}\text { Through qualitative methods and together with HEPs, } \\
\text { and WHDA leaders recruiting deviants and qualified } \\
\text { by training on module-I and II }\end{array}$ \\
\hline 4. & $\begin{array}{l}\text { Personalized and } \\
\text { comprehensive } \\
\text { informational counseling and } \\
\text { social support }\end{array}$ & $\begin{array}{l}\text { Positive } \\
\text { deviants }\end{array}$ & $\begin{array}{l}\text { Community based-home-to- } \\
\text { home visit }\end{array}$ & $\begin{array}{l}\text { Informational counseling and social support to } \\
\text { mothers together with their family or relevant others } \\
\text { on EBF practice }\end{array}$ \\
\hline S.No & Module/Content & \multicolumn{2}{|c|}{ Time of exposure/visit } & Duty of PDs per Visit \\
\hline 1) & Module-I & \multicolumn{2}{|c|}{ Ist visit (38th wk of GA) } & Refer below in module-I \\
\hline 2) & Module-I and II & \multicolumn{2}{|c|}{$\begin{array}{l}\text { 2nd visit (Ist day of delivery or return from } \\
\text { health facility) }\end{array}$} & Refer below in module-I and II \\
\hline 3) & Module-II & \multicolumn{2}{|c|}{ 3rd visit (end of Ist month) } & Refer below in module-II \\
\hline 4) & Module-II & \multicolumn{2}{|c|}{4 th visit (end of 2 nd month) } & Refer below in module-II \\
\hline 5) & Module-II & \multicolumn{2}{|c|}{5 th visit (end of 3 rd month) } & Refer below in module-II \\
\hline 6) & Module-II & \multicolumn{2}{|c|}{ 6th visit (end of 4th month) } & Refer below in module-II \\
\hline \multicolumn{5}{|c|}{ Module one (informational support) } \\
\hline \multicolumn{5}{|c|}{$\begin{array}{l}\text { A. Developing an empathic relationship: } \\
\text { - Greeting the family, take seat, self-introduction and start a conversation about the general newborn care and EBF } \\
\text { - Building trust, safe, alliance with the mother and other family members. }\end{array}$} \\
\hline \multicolumn{5}{|c|}{$\begin{array}{l}\text { B. Collaborating with the family as a partnership: } \\
\text { - The PDs brought skills and knowledge of EBF issues and the family brought their own experience and resources to discuss and reach a consensus. }\end{array}$} \\
\hline \multicolumn{5}{|c|}{$\begin{array}{l}\text { C. Using guided discovery: } \\
\text { - A style of engagement to both gentle probe for the individual and family's BF beliefs, and to stimulate alternative ideas. Then appropriate use of } \\
\text { "information" } \\
\text { - What are the beliefs and subjective norms that prevailed about EBF at the individual and community level? } \\
\text { - What looks like the general newborn caring practice? Such as personal hygiene, maternal feeding, etc. } \\
\text { - What is an exclusive BF practice? Why and how practiced? } \\
\text { - Initiation? }\end{array}$} \\
\hline
\end{tabular}


Table I (Continued).

Module two (Emotional and appraisal support)

A. Putting knowledge into practice and behavioral activation:

Recap major concepts discussed previously (verification of understanding)

Checking whether the mother tried things out in between counseling sessions, putting what had been learned in the last visit

The lived best experiences of PDs would be explained and shared

Psychosocial support and verification of her understanding of EBF.

How to express and feed breast milk when the mother busy/go to work?-PDs were trained on manual expression techniques and steps.

What are the danger signs of the newborn in the process of general caring?

B. Working with key family members

This helped to motivate and encourage mothers to take small steps and then build on these. Identifying the most relevant others for the mother and engaging them.

\section{Problem-solving:}

Problems and barriers inputting new knowledge and skills into practice would be analyzed, communicated soon, and solved.

Emotional and appraisal support.

\section{Analyzing challenges and giving feedback}

They analyzed what the mother challenged and give feedback.

newborn/infant, experience with best caring practices used and expectations, beliefs, and myths related to newborn/infant care including EBF. The first thing is to develop an empathic relationship such as trusting, safe, alliance with the mother and other family members. Collaborating with the family in an equal partnership such as the PDs might bring skills and knowledge of EBF issues and the family brought their own experience and resources. A style of engagement was gently probing from the individual and family's BF beliefs, attitude and to stimulate alternative ideas. Hence, deviants used "information" effectively to make culturally appropriate illustrations so that to facilitate communication with mothers and families. Putting knowledge into practice and behavioral activation means the mother tried things out in between counseling sessions, putting what had been learned into practice. PDs worked with key family members to motivate and encourage mothers to take small steps and then build on these. They tried to solve problems and barriers inputting and analyzing new knowledge and skills into practice and communicated soon. Then, every month the PI collected feedback about each visiting session from PDs if they challenged with some technical and medical issues of BF. The information gathering checklist contains confirmation of the presence of the positive deviant per schedule (both mother and deviant put sign), discussion points raised, any difficulty on technical and medical issues of $\mathrm{BF}$, the way forward, the next time of visit and challenges faced. This intervention was in addition to the already existing routine community-based services.

\section{For Control Group}

Mothers enrolled in the control group received the usual routine prenatal and postpartum services provided by health extension professionals either at health post or in the community through home visits.

\section{Data Collection Tool and Procedure}

Interviewer-administered structured questionnaire was adapted in English, and translated into two local languages-Afan Oromo and Amharic, then back translated by independent language expert to check consistency. The tool which was used to assess the change at three points in time had three parts. Part-I of the questionnaire assessed the baseline characteristics of the mothers such as socio-demographics, obstetric history, previous experience of receiving home visits and social support, main source of information about EBF, and intention to $\mathrm{BF}$ for the current baby. Part-II assessed ideation factors of EBF such as knowledge (definition, advantage to baby, advantage to mother, colostrum, effective feeding, breast milk expression, initiation, duration and frequency of feeding, 
problems with $\mathrm{BF}$, practical aspects of $\mathrm{BF}$ and exclusiveness), attitude (affective, behavioral and subjective norms related with EBF), and self-efficacy (confidence and capability to practice $\mathrm{EBF}$, technique of $\mathrm{BF}$, and effective $\mathrm{BF}$ ). Face validity was conducted including for the self-efficacy measuring items since it was adapted with some modification. This part of the tool was adapted from reliable and validated sources. ${ }^{34,35}$ The final (part-III) consisted of items measuring EBF practice based on WHO standards. ${ }^{36}$ The questionnaire was pre-tested on $5 \%$ $(n=13)$ of the sample out of the study clusters. Based on the comments and feedback collected, relevant modifications were made.

Six data collectors (one for each cluster), who had a college degree in a health-related field and relevant experience, were recruited to conduct the interviews. Two public health experts (MPH) were recruited to supervise the data collection process. Data collectors and supervisors received training for 3 days. Data were collected at three points in time-from both the intervention and control groups. Supervisors' and principal investigator provided oversight for the data collection and fieldwork and checked samples of completed questionnaires. The same data collectors who were blinded (not informed to which cluster/group assigned) collected the baseline, midline, and end-line data to minimize interviewer bias.

Each study participant had a unique identification number and contact details to trace at each point of data collection. The enrollers, data collectors, counselors/PDs, and supervisors are different individuals. The enrollment period, data collection frequency and content, and followup were the same in both groups except the added intervention provided to the intervention group. The baseline data were collected at 37 weeks of gestation before the intervention. Then, the first, second, third, fourth, fifth, and sixth visit were conducted at 38-40 weeks of gestation, first day of delivery, first, second, third, and fourth month of postpartum, respectively. The midline and endline data were collected at third and sixth month of postpartum, respectively.

\section{Data Analysis}

Data were entered into Epidata 3.1 and then exported to SPSS version 21.0 for analysis. Baseline characteristics were summarized using proportions for categorical variables, and means or medians for continuous variables. Descriptive statistics were presented as the mean $\pm \mathrm{SD}$ or frequencies with percentage. All quantitative data were checked for normality using the Shapiro-Wilk test and/ or histogram as appropriate. Responses to each variable were compared between the two groups across three points in time. To compare the baseline characteristics and intervention effect, a $\chi^{2}$-test or Fisher exact test for dichotomous, and independent sample $t$-test for continuous measures, were used to estimate the significant difference at $95 \% \mathrm{CI}$ with $\mathrm{P}$-values of $<0.05$. The tests were used to check for significant differences in the primary and secondary outcome variables between the groups. Intention to treat analysis was used so that all enrolled mothers were included in the final analysis. In addition, difference-in-difference was calculated to determine the net effect of the intervention in percentage points. The magnitude of the intervention effect on the outcome (EBF) was estimated using the adjusted rate risk (relative risk). General Linear Model (GLM) considering repeated measures was applied, and the respective 95\% confidence intervals with the p-value at a level of $5 \%$ significance were provided. The multivariate models were fitted by adjusting for occupational status, ever BF, menses return, and duration of suckling breast (in minutes) among the intervention and control groups since there were significant differences at baseline. Those factors/covariates were not controlled at baseline that might have effect on the outcome. This was controlled through Analysis of Covariance (ANCOVA) and Multiple Analysis of Covariance (MANCOVA), which are GLM methods blending ANOVA and regression. These evaluates whether the means/proportions of a dependent variable were equal across levels of a categorical independent variable (intervention), while statistically controlling for the effects of other continuous and dichotomous variables that were not of primary interest.

\section{Ethical Consideration}

Ethical approval or clearance letter was secured from the Institutional Review Board (IRB), Jimma University, Institute of Health with Ref. No: IHRPGD/2095/2018 and dated as $22 / 01 / 2018$. Permission and support letters were obtained from Jimma town health office and respective health facilities. Written informed consent was obtained after subjects were informed about their full right to participate or refuse participation in the study. The data collectors explained every trial procedure and follow-up time using an information sheet. Participants were also informed about their right to withdraw at any time during the intervention and follow-up 
period if not feeling comfortable, keeping in mind the rationale of the study and benefits of their response to the study. Informed consent was also obtained from each mother enrolled into the intervention arm for visit at her home by positive deviants and data collectors. No mother withdrew/refrained from their consent during follow-up, and no missed visit was reported from the schedule since revisit made for some mothers. When PDs observe health problems with newborns and/or mothers, they linked them with the HEPs for further counseling and referral if needy. Codes were used to keep the anonymity and to link each subject's followup data. This study was conducted in accordance with the Declaration of Helsinki.

\section{Results}

Response rates for both groups were $100 \%$ and $99.2 \%$ at baseline and midline, respectively. The response rate at the endline, however, was $99.2 \%$ for the control group and $98.5 \%$ for the intervention group. One mother in the control group was lost to follow-up in the second month and two mothers were lost to follow-up in the intervention group near to third and after fourth months due to change of living address and death.

\section{Background Characteristics}

Out of 260 mothers enrolled in the study, nearly half (45.4\%) were 25-29 years old, with the average age at 25.58 years. Forty-one percent were Orthodox Christians and $44.6 \%$ were Oromo. Near to all of the mothers $(96.2 \%)$ were married and the majority $(70.8 \%)$ were literate or had received a formal education, with $63 \%$ having completed secondary school. Over a third were employed as merchants (36.5\%) and $42.7 \%$ had a monthly income of 22.03USD or less. Seventy-one percent of the mothers had given birth to only one child at baseline (Table 2).

There were no statistically significant differences between the two groups along with socio-demographic characteristics except occupational status: more than a third of the mothers in the intervention group were government employees, while $44.6 \%$ in the control group were merchants $(\mathrm{P}=0.001)$. In addition to this, there were no statistically significant differences with obstetric variables, baby's sex preference, previous experience of receiving a home visit and social support from different individuals, source of information about EBF, and intention to BF for the current baby between the two groups (Table 2).

\section{Ideation Factors of Breastfeeding}

There were no significant differences between the groups on ideation factors of BF such as knowledge, attitude, and self-efficacy at baseline. The respective proportions in both groups were decreased from knowledge to attitude and then to self-efficacy at the three time points. Unlike the baseline, there were statistically significant differences observed on these ideation factors at midline and endline. The percentage of mothers in the intervention group who had good knowledge significantly increased by 16 points from baseline to midline and then increased by 20 points to endline, while increased by 7 points in the control group from baseline to endline. The percentage of mothers reported favorable attitude significantly increased by 22 points in the intervention group from baseline to endline, while remained almost the same in the counterparts. The percentage of mothers in the intervention group who had good self-efficacy significantly increased by 28 points from baseline to midline and then increased by 33 points to endline, while increased by 5 points in the control group from baseline to endline. Out of the three ideation factors, the maximum positive increment was reported in changing mothers' self-efficacy (Table 3).

\section{Breastfeeding Practices and Exclusiveness}

The intervention group showed improvements at midline for key BF practices. All mothers in the intervention group said that they had ever BF at midline and endline compared to $89.2 \%$ at baseline, which was significantly higher proportion compared to the control group. The proportion of mothers in the intervention group who BF within 24 hours of birth increased significantly by 27 percentage point at midline from the baseline while increased by 2 points in the counterparts. Significantly a higher proportion of mothers in the intervention group reported EBF within the last 24 hours from the survey date as compared to the control group at midline and endline. The proportion of mothers in the intervention group who practice EBF within the last 24 hours increased from baseline $(42.3 \%)$ to midline $(71.3 \%)$, and then decreased to endline (66.4\%), while consistently decreased in the counterparts. The proportion of mothers in the intervention group who reported EBF practice in the first 3 or 6 months increased from baseline $(32.3 \%)$ to midline (58.1\%) by 26 points and then decreased to endline (50.8\%) by 7 points with statistically significant differences between the two groups. No significant difference in practicing pre-lacteal feeding, while 
Table 2 Comparing the Background Characteristics of the Intervention and Control Group, Implementation Study, Jimma Town, 2018 $(n=260,130$ in Each Group)

\begin{tabular}{|c|c|c|c|c|}
\hline \multicolumn{2}{|l|}{ Variables with/without Category } & $\begin{array}{l}\text { Intervention Group (IG): N } \\
(\%) /(\text { Mean } \pm \text { SD) }\end{array}$ & $\begin{array}{l}\text { Control Group (CG): N } \\
\text { (\%)/(Mean } \pm \text { SD) }\end{array}$ & P-value \\
\hline \multicolumn{2}{|l|}{ Age } & $25.9 \pm 3.7$ & $25.2 \pm 4.3$ & 0.135 \\
\hline Religion & $\begin{array}{l}\text { Orthodox } \\
\text { Muslim } \\
\text { Protestant } \\
\text { Catholic } \\
\text { Other* }\end{array}$ & $\begin{array}{l}55(42.3) \\
5 I(39.2) \\
22(16.9) \\
I(0.8) \\
I(0.8)\end{array}$ & $\begin{array}{l}53(40.8) \\
51(39.2) \\
16(12.3) \\
4(3.1) \\
6(4.6)\end{array}$ & 0.192 \\
\hline Ethnic group & $\begin{array}{l}\text { Oromo } \\
\text { Amhara } \\
\text { Yem } \\
\text { Dawuro } \\
\text { Kaffa } \\
\text { Other** }\end{array}$ & $\begin{array}{l}58(44.6) \\
31(23.8) \\
16(12.3) \\
13(10.0) \\
8(6.2) \\
4(3.1)\end{array}$ & $\begin{array}{l}58(44.6) \\
25(19.2) \\
27(20.8) \\
4(3.1) \\
7(5.4) \\
9(6.9)\end{array}$ & 0.068 \\
\hline Marital status & $\begin{array}{l}\text { Married } \\
\text { Divorced } \\
\text { Widowed } \\
\text { Single }\end{array}$ & $\begin{array}{l}\text { I27 (97.7) } \\
1(0.8) \\
0(0.0) \\
2(1.5)\end{array}$ & $\begin{array}{l}123(94.6) \\
4(3.1) \\
1(0.8) \\
2(1.5)\end{array}$ & 0.388 \\
\hline Educational status & $\begin{array}{l}\text { Illiterate } \\
\text { Literate }\end{array}$ & $\begin{array}{l}42(32.3) \\
88(67.7)\end{array}$ & $\begin{array}{l}34(26.2) \\
96(73.8)\end{array}$ & 0.340 \\
\hline Occupational status & $\begin{array}{l}\text { Housewife } \\
\text { Merchant } \\
\text { Student } \\
\text { Govt. employee } \\
\text { Other*** }\end{array}$ & $\begin{array}{l}42(32.3) \\
37(28.5) \\
2(1.5) \\
45(34.6) \\
4(3.1)\end{array}$ & $\begin{array}{l}27(20.8) \\
58(44.6) \\
19(14.6) \\
20(15.4) \\
6(4.6)\end{array}$ & 0.001 \\
\hline Monthly income $(\mathrm{ETB})^{\#}$ (overall median & $=800)$ & $1112 \pm 1104.7$ & $1297.9 \pm 1448.2$ & 0.246 \\
\hline Parity (overall median=I) & & $1.5 \pm 0.8$ & $1.3 \pm 0.6$ & 0.065 \\
\hline Preference for sex of the baby & $\begin{array}{l}\text { Not prefer } \\
\text { Prefer-F } \\
\text { Prefer-M }\end{array}$ & $\begin{array}{l}8565.4) \\
24(18.5) \\
21(16.2)\end{array}$ & $\begin{array}{l}79(60.8) \\
23(17.7) \\
28(21.5)\end{array}$ & 0.058 \\
\hline Place of delivery & $\begin{array}{l}\text { HI } \\
\text { Home }\end{array}$ & $\begin{array}{l}108(83.1) \\
22(16.9)\end{array}$ & $\begin{array}{l}104(80) \\
26(20)\end{array}$ & 0.125 \\
\hline Mode of delivery & $\begin{array}{l}\text { VD } \\
C / S\end{array}$ & $\begin{array}{l}\text { III(85.4) } \\
19(14.6)\end{array}$ & $\begin{array}{l}114(87.7) \\
16(12.3)\end{array}$ & 0.144 \\
\hline $\begin{array}{l}\text { Received home visit from HEPs at } \\
\text { least once }\end{array}$ & $\begin{array}{l}\text { Yes } \\
\text { No }\end{array}$ & $\begin{array}{l}21(16.2) \\
109(83.9)\end{array}$ & $\begin{array}{l}26(20) \\
104(80)\end{array}$ & 0.132 \\
\hline $\begin{array}{l}\text { Received home visit from model } \\
\text { mother at least once }\end{array}$ & $\begin{array}{l}\text { Yes } \\
\text { No }\end{array}$ & $\begin{array}{l}16(12.3) \\
114(87.7)\end{array}$ & $\begin{array}{l}18(13.9) \\
112(86.2)\end{array}$ & 0.546 \\
\hline Received support from relevant others & $\begin{array}{l}\text { Yes } \\
\text { No }\end{array}$ & $\begin{array}{l}78(60) \\
52(40)\end{array}$ & $\begin{array}{l}84(64.6) \\
46(35.4)\end{array}$ & 0.076 \\
\hline
\end{tabular}


Table 2 (Continued).

\begin{tabular}{|c|c|c|c|c|}
\hline \multicolumn{2}{|c|}{ Variables with/without Category } & \multirow{2}{*}{$\begin{array}{l}\text { Intervention Group (IG): N } \\
\text { (\%)/(Mean } \pm \text { SD) } \\
25(19.2) \\
20(15.4) \\
43(33.1) \\
40(30.8) \\
2(1.5)\end{array}$} & \multirow{2}{*}{$\begin{array}{l}\text { Control Group (CG): N } \\
(\%) /(\text { Mean } \pm \text { SD) } \\
23(17.7) \\
22(16.9) \\
48(36.9) \\
35(26.9) \\
2(1.5)\end{array}$} & \multirow{2}{*}{$\begin{array}{l}\text { P-value } \\
0.145\end{array}$} \\
\hline $\begin{array}{l}\text { Main source of information } \\
\text { about EBF }\end{array}$ & $\begin{array}{l}\text { UHEPs } \\
\text { Family } \\
\text { HPs } \\
\text { Mass media } \\
\text { Other }\end{array}$ & & & \\
\hline Intention to BF & $\begin{array}{l}\text { Yes } \\
\text { No }\end{array}$ & $\begin{array}{l}112(86.2) \\
18(13.8)\end{array}$ & $\begin{array}{l}114(87.7) \\
16(12.3)\end{array}$ & $0.54 I$ \\
\hline
\end{tabular}

Notes: Other*=Adventist, Jobs; Other**=Guragie, Silte, Tigrie; Other***=self-employed, farmer, private sector employee; ${ }^{*} I$ IUSD=27.24ETB during the study period.

there was in feeding expressed breast milk at midline and endline time (Table 4).

\section{Indirect Measures of BF Intensity}

There were significant differences among the two groups concerning menses return, bottle feeding practices, frequency of BF during night and day times, and duration of suckling breast. At the three points, the proportions of mothers whose menses returned and who reported duration of suckling were significantly different in both groups with percentage decrements in the second and third points in the intervention groups while almost the same in control groups. Menses return time, and bottle feeding practice in the intervention group were decreased by $48.6 \%$ and $64.2 \%$ respectively from baseline to endline. The proportion of mothers in the intervention group who reported BF between four and six per night increased from baseline to midline by $15.7 \%$ and to endline by $21.6 \%$. However, with the same range of feeding frequency during day-times, the proportions decreased from baseline to midline and endline by $25.5 \%$ and $28.6 \%$, respectively. The increased frequency during night-times and decrement during day- times showed the inconsistent and imbalanced BF practices per 24 hours of the day. This means the nighttime BF practice is more intensive than the daytime, which is expected to be $4-6$ times per half of the day. The proportion of infants among intervention groups on the medium duration of suckling was increased by $11.6 \%$ and $35.2 \%$ from baseline to midline and endline, respectively, while minimal increment was observed in the control groups (Table 5).

\section{Changes in EBF Practices}

There were positive changes in all indicators of BF practice for the intervention group. The EBF rate increased by $+18.5 \%$ in the intervention group, while $+0.2 \%$ in control groups. The positive improvements in the intervention group were greater than $1 \%$ for all indicators except for the mean frequency of $\mathrm{BF}$. The greatest change in the intervention group was in the initiation of BF, which increased by nearly 23 percentage points from the baseline unlike in the control group which decreased by almost 23 points. The net effect (difference-in-difference) was 18.2\% in practicing $\mathrm{EBF}$ for the first 6 months. In addition, the

Table 3 Summary of Ideation Factors of EBF Between the Intervention and Control Groups Across the Three Time Points, Implementation Study, Jimma Town, 2018

\begin{tabular}{|c|c|c|c|c|c|c|c|c|c|c|}
\hline \multirow{2}{*}{\multicolumn{2}{|c|}{$\begin{array}{l}\text { Variables (Ideation } \\
\text { Factors) }\end{array}$}} & \multicolumn{3}{|c|}{ Baseline } & \multicolumn{3}{|c|}{ Midline } & \multicolumn{3}{|c|}{ Endline } \\
\hline & & IG: N(\%) & CG: N(\%) & P-value & IG: N(\%) & CG: N(\%) & P-value & IG: N(\%) & CG: $\mathbf{N}(\%)$ & P-value \\
\hline Knowledge & $\begin{array}{l}\text { Good } \\
\text { Poor }\end{array}$ & $\begin{array}{l}78(60) \\
52(40)\end{array}$ & $\begin{array}{l}76(58.5) \\
54(41.5)\end{array}$ & 0.667 & $\begin{array}{l}98(76) \\
31(24)\end{array}$ & $\begin{array}{l}83(64.3) \\
46(35.7)\end{array}$ & 0.01 & $\begin{array}{l}103(80.5) \\
25(19.5)\end{array}$ & $\begin{array}{l}84(65.1) \\
45(34.9)\end{array}$ & 0.001 \\
\hline Attitude & $\begin{array}{l}\text { Favorable } \\
\text { Unfavorable }\end{array}$ & $\begin{array}{l}65(50) \\
65(50)\end{array}$ & $\begin{array}{l}48(36.9) \\
82(63.1)\end{array}$ & 0.054 & $\begin{array}{l}92(71.3) \\
37(28.7)\end{array}$ & $\begin{array}{l}47(36.4) \\
82(63.6)\end{array}$ & 0.001 & $\begin{array}{l}93(72.7) \\
35(27.3)\end{array}$ & $\begin{array}{l}46(35.7) \\
83(64.3)\end{array}$ & 0.001 \\
\hline Self-efficacy & $\begin{array}{l}\text { Good } \\
\text { Poor }\end{array}$ & $\begin{array}{l}56(43.1) \\
74(56.9)\end{array}$ & $\begin{array}{l}47(36.2) \\
83(63.9)\end{array}$ & 0.052 & $\begin{array}{l}92(71.3) \\
37(28.7)\end{array}$ & $\begin{array}{l}52(40.3) \\
77(59.7)\end{array}$ & 0.01 & $\begin{array}{l}98(76.6) \\
30(23.4)\end{array}$ & $\begin{array}{l}54(41.9) \\
75(58.1)\end{array}$ & 0.01 \\
\hline
\end{tabular}




\begin{tabular}{|c|c|c|c|c|c|c|c|c|}
\hline & & 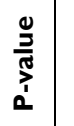 & $\bar{\alpha}$ & $\overline{0}$ & $\frac{\simeq}{0}$ & $\bar{\circ}$ & 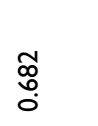 & $\bar{\circ}$ \\
\hline & 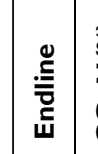 & $\begin{array}{l}\stackrel{Ð}{\check{z}} \\
\text { ü }\end{array}$ & 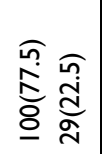 & 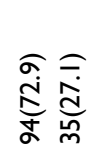 & 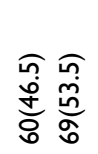 & $\begin{array}{ll}\widehat{\bar{m}} & \widehat{\sigma} \\
\text { o d } & \text { o }\end{array}$ & 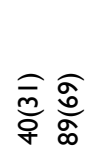 & 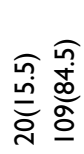 \\
\hline & & $\begin{array}{l}\widehat{o} \\
\mathbf{z} \\
\underline{\ddot{o}}\end{array}$ & 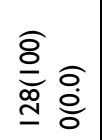 & 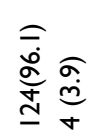 & 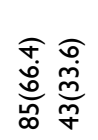 & 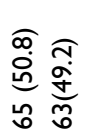 & 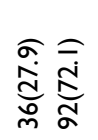 & 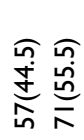 \\
\hline & & 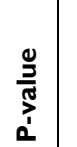 & $\bar{\delta}$ & $\begin{array}{l}\overline{0} \\
\dot{0}\end{array}$ & $\underset{\tilde{\delta}}{\tilde{0}}$ & $\overline{\tilde{m}}$ & 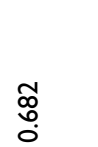 & $\stackrel{\simeq}{\circ}$ \\
\hline & 吝 & $\begin{array}{l}\text { 巳̊ } \\
\ddot{0} \\
\text { d }\end{array}$ & 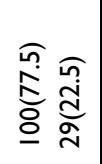 & 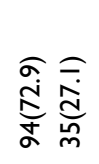 & 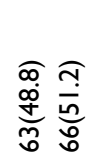 & 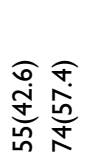 & 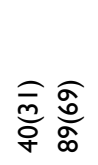 & 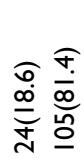 \\
\hline & & $\begin{array}{l}\widehat{O} \\
\underline{Z} \\
\underline{\ddot{o}}\end{array}$ & 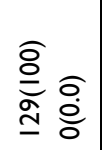 & 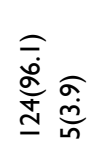 & 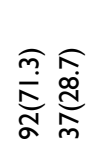 & 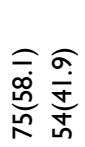 & 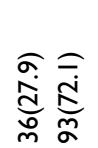 & 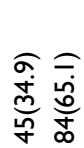 \\
\hline & & 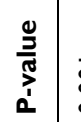 & $\overline{8}$ & $\begin{array}{c}\bar{m} \\
\stackrel{m}{0}\end{array}$ & $\begin{array}{l}\text { 员 } \\
\text { O. }\end{array}$ & $\begin{array}{l}\stackrel{n}{0} \\
\stackrel{m}{0}\end{array}$ & $\begin{array}{l}\stackrel{2}{2} \\
\text { Oे }\end{array}$ & 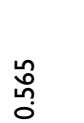 \\
\hline & 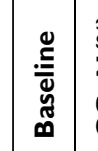 & 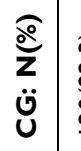 & 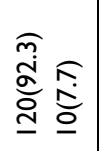 & 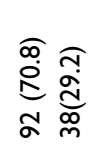 & 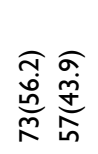 & 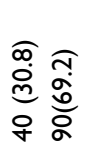 & 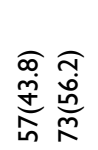 & 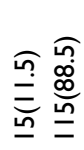 \\
\hline & & $\begin{array}{l}\widehat{o} \\
\grave{z} \\
\underline{\ddot{g}}\end{array}$ & 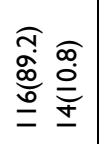 & 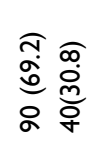 & 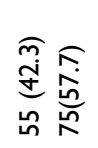 & 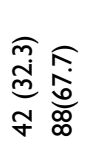 & 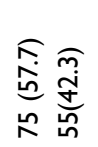 & 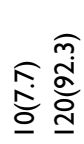 \\
\hline & & & $\stackrel{y}{\check{\nu}}$ & $\stackrel{y}{\check{\nu}}$ & 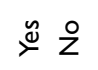 & $\stackrel{y}{\longleftarrow}$ & 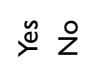 & 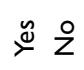 \\
\hline & 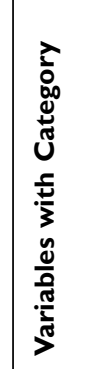 & & 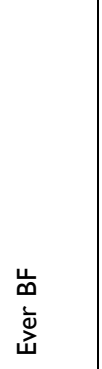 & 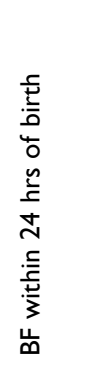 & 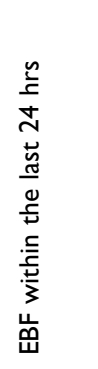 & 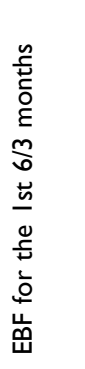 & 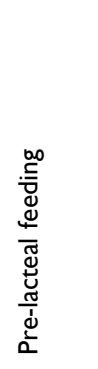 & 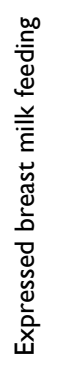 \\
\hline
\end{tabular}

net effect of the intervention on timely initiation of complementary feeding rate was increased by $16.7 \%$ in the intervention groups compared to counterparts (Table 6).

There was no significant difference at baseline in practicing EBF, while there were increments in both groups till the third month of postpartum with different rates. Finally, there was a decline in both groups with different rates. From the initial point to the end point, the proportion of mothers who practice EBF was above/over the controlled group. EBF practice increased in the intervention group from baseline (32.3\%) to midline $(58.1 \%)$ and then decreased to endline $(50.8 \%)$ with higher rate as compared to control group (Figure 2).

The multivariate analysis of covariance was done through the GLM regression method by considering intention-to-treat analysis (260 mothers included to the final model). At baseline, the relative risk of avoiding EBF (Adjusted RR: 1.112, 95\% CI: 0.645-1.964, $\mathrm{P}=0.679$ ), practicing pre-lacteal feeding (ARR: 1.100, 95\% CI: 0.335-1.877, $\mathrm{P}=0.886$ ), and bottle feeding (ARR: 1.101, 95\% CI: $0.556-1.899, \mathrm{P}=0.698)$ were similar among the two groups-no significant difference observed. At followup, however, mothers in the intervention group were 2 times more likely to practice EBF (ARR: $2.294,95 \%$ CI: 1.363-4.561, $\mathrm{P}=0.003$ ), and 2 times more likely to initiate timely complementary feeding practice (ARR: $2.124,95 \%$ CI: $1.234-3.251, \mathrm{P}=0.012$ ) compared to the counterparts. In another way, mothers in the intervention group were 3 times more likely to avoid bottle feeding (ARR: 3.245, 95\% CI: $1.863-4.861, \mathrm{P}=0.001)$ compared to those in the control groups. However, there was no significant difference between the groups with risk of practicing pre-lacteal feeding rate (ARR: $1.111,95 \% \mathrm{CI}$ : $0.845-1.864, \mathrm{P}=0.779$ ) even after the intervention.

\section{Discussion}

The findings of this study showed that the PDA had the intended-desirable effect on improving EBF practices. Mothers in the intervention group had a better practice of EBF, duration of feeding, frequency of feeding, and timely initiation of complementary feeding compared to the control group. Hence, PDA was effective in improving proportion of EBF practice. There were positive changes in all standard indicators of $\mathrm{BF}$ practice for the intervention group. The net change difference of EBF rate in the intervention group increased by 18 points, which is more than the expected effect size at the design stage, compared to the control group for which almost no change was observed. The positive improvements in the intervention 


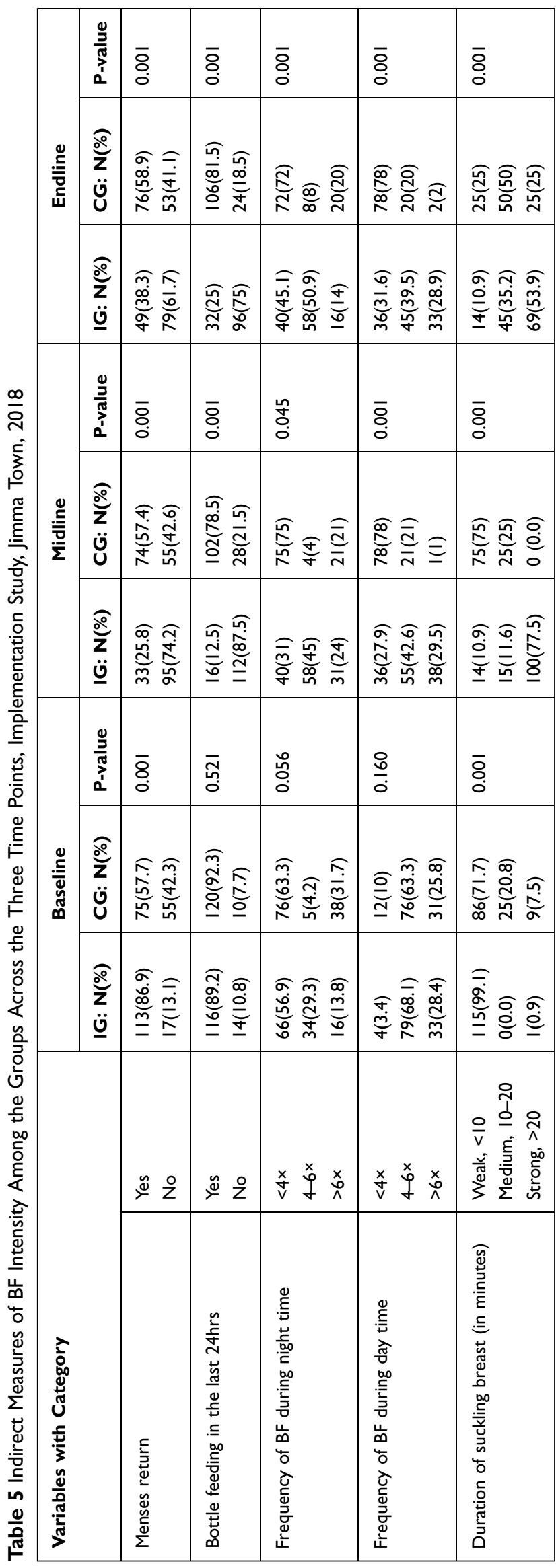

group were greater than $1 \%$ for all indicators except for the mean frequency of BF, unlike the counterparts.

This finding remained significant after controlling relevant baseline characteristics of the mothers, which is supported by an earlier study ${ }^{37}$ in that a community-based intervention improved BF practices. The acceptance and support for the PDA by the implementers, community members, mothers, spouses, relevant others, and relatives may have contributed for the effectiveness of this approach. Consistently, a systematic review ${ }^{38}$ also concluded that counseling, education and peer support considering the culture and local resources can improve EBF starting from the initiation to sustained duration. However, our intervention was not effective in significantly decreasing pre-lacteal feeding, improving intensified BF practice and mean frequency of BF. We were not able to explain the non-significant difference but higher decrement in the intervention group and lower decrement in the counterparts such as why and how pre-lacteal feeding decreased in the control group.

Paradoxically, the positive findings in this study refute reports of communitywide interventional studies conducted in Australia and Guatemala. ${ }^{39,40}$ These studies revealed that there was no significant difference observed on initiation and exclusiveness of BF, although there was increment in the proportion of EBF which suggested that communitywide programs become more effective over time. However, in our study, the positive deviance approach was proved to be effective both in the shortand long-term periods as compared to the baseline. We argue that an effective community-based intervention demands appropriate design, and consideration of the context to which PDA fit. We have ensured this by our participatory design while planning the intervention at the community level. In addition, implementation fidelity might be one of the contributing factors for the observed effectiveness in our study. Our team exerted maximum efforts to ensure sufficient time and dosage of the intervention. Hence, the good adherence and compliance to the protocol might help us to celebrate its effectiveness. To achieve optimal BF practices, giving equal or prior attention to social factors of women about BF is needed as of addressing systemic and health factors.

The change in the proportions of EBF at the third and sixth months of postpartum from the baseline to midline $(+26 \%)$ and endline $(+19 \%)$ were much more than the assumed effect size at the design of this study. This finding is unlike that of the Guatemala study which reported only 
Table 6 Comparison of BF Practice Measures Between the Intervention and Control Groups, Jimma Town, 2018

\begin{tabular}{|c|c|c|c|c|c|c|c|}
\hline \multirow[t]{2}{*}{ EBF Indicators } & \multicolumn{2}{|c|}{ Baseline } & \multicolumn{2}{|c|}{ Midline } & \multicolumn{2}{|c|}{ Endline } & \multirow{2}{*}{$\begin{array}{c}\text { Rate } \\
\text { Change (in } \\
\%)^{*}\end{array}$} \\
\hline & $\begin{array}{l}\text { IG: N (\%)/ } \\
\text { Mean } \\
\text { (士SD) }\end{array}$ & $\begin{array}{l}\text { CG:N } \\
\text { (\%)/Mean } \\
\text { (士SD) }\end{array}$ & $\begin{array}{l}\text { IG: N (\%)/ } \\
\text { Mean } \\
\text { (士SD) }\end{array}$ & $\begin{array}{l}\text { CG: N (\%)/ } \\
\text { Mean (士SD) }\end{array}$ & $\begin{array}{l}\text { IG: N (\%)/ } \\
\text { Mean(士SD) }\end{array}$ & $\begin{array}{l}\text { CG: } \mathbf{N}(\%) / \\
\text { Mean (士SD) }\end{array}$ & \\
\hline EBF rate & $42(32.3)$ & $40(30.8)$ & $75(58.1)$ & $55(42.6)$ & $65(50.8)$ & $40(3 I)$ & $\begin{array}{l}\mathrm{I}(+\mid 8.5) \\
\mathrm{C}(+0.2)\end{array}$ \\
\hline Predominant BF rate & $63(48.5)$ & $60(46.2)$ & $55(42.6)$ & $62(48.1)$ & $46(35.9)$ & $73(56.6)$ & $\begin{array}{l}I(-12.5) \\
C(+10.4)\end{array}$ \\
\hline Never BF rate & $14(10.8)$ & $10(7.7)$ & $0(0.0)$ & $29(22.5)$ & $0(0.0)$ & $29(22.5)$ & $\begin{array}{l}I(-10.8) \\
C(+\mid 4.8)\end{array}$ \\
\hline $\begin{array}{l}\text { Initiation of BF in the } \\
\text { first hour of life (rate) }\end{array}$ & $45(35.4)$ & $65(50)$ & $78(60.5)$ & $35(27.1)$ & $78(60.5)$ & $35(27.1)$ & $\begin{array}{l}\mathrm{I}(+25.1) \\
\mathrm{C}(-22.9)\end{array}$ \\
\hline $\begin{array}{l}\text { Mean duration of EBF } \\
\text { (months) }\end{array}$ & $4.2( \pm 2.1)$ & $5.3( \pm I .2)$ & $2.8( \pm 0.2)$ & $2.0( \pm I)$ & $5.3( \pm 0.7)$ & $4.5( \pm 1.5)$ & $\begin{array}{l}I(+I . I) \\
C(-0.8)\end{array}$ \\
\hline $\begin{array}{l}\text { Mean frequency of BF in the } \\
\text { last } 24 \text { hrs (hours) }\end{array}$ & $8.9( \pm 3.3)$ & $10.3( \pm 5.6)$ & $9.9( \pm 2.5)$ & $7.5( \pm 3.2)$ & $9( \pm \mid .2)$ & $8.1( \pm 2.5)$ & $\begin{array}{l}\mathrm{I}(+0.1) \\
\mathrm{C}(-2.2)\end{array}$ \\
\hline $\begin{array}{l}\text { Mean duration of lactational } \\
\text { amenorrhea (months) }\end{array}$ & $3.6( \pm 1.8)$ & $3.4( \pm 2)$ & $2.9( \pm 0.1)$ & $2( \pm I)$ & $5.8(0.2)$ & $3.5(1.5)$ & $\begin{array}{l}I(+2.2) \\
C(+0.1)\end{array}$ \\
\hline Pre-lacteal feeding rate & $75(57.7)$ & $57(43.8)$ & $36(27.9)$ & $40(31)$ & $36(28.1)$ & $40(3 I)$ & $\begin{array}{l}\text { I }(-29.6) \\
C(-12.8)\end{array}$ \\
\hline Partial/mixed BF rate & $74(56.9)$ & $80(61.5)$ & $54(4 I .9)$ & $45(34.9)$ & $63(49.2)$ & $60(46.5)$ & $\begin{array}{l}\mathrm{I}(-7.7) \\
\mathrm{C}(-15)\end{array}$ \\
\hline Bottle feeding rate & $116(89.2)$ & $120(92.3)$ & $16(12.5)$ & $102(78.5)$ & $32(25)$ & $106(81.5)$ & $\begin{array}{l}\mathrm{I}(-64.2) \\
\mathrm{C}(-10.8)\end{array}$ \\
\hline $\begin{array}{l}\text { Complementary feeding rate } \\
\text { (at } 6 \text { months) }\end{array}$ & $4 \mid(3 I .5)$ & $37(28.5)$ & - & - & $65(50.8)$ & $40(31)$ & $\begin{array}{l}\mathrm{I}(+19.2) \\
\mathrm{C}(+2.6)\end{array}$ \\
\hline
\end{tabular}

Note: *Rate change=(Endline proportion) - (Baseline proportion) for each group.

Abbreviations: I, intervention group; C, control group.

$+2.1 \%$ increment in the intervention group while $-3.9 \%$ in the control group. ${ }^{40}$ This indicates that simple mother-tomother support may not be effective unless positive deviants and deviated behaviors are identified and intervened accordingly. The higher increment of proportion from the baseline to the midline and declining from the midline to the endline was inconsistent with what the Guatemala study reported. That study revealed sharp decrement from $29 \%$ to $23 \%$ then to $12 \%$ unlike ours. Basically, EBF is expected to increase in the first few months and decrease while postpartum period goes forward. This means every mother tries their level best to feed their breast in the first few months due to cultural support and motherhood exercise as shown in the control group. This might result in increased proportions in both groups till the third month. Then, to sustain EBF practice requires better knowledge, favorable attitude, good self-efficacy, and social support from relevant others and PDs. Courage to solve work-related challenges and self-positioning (strong stand) against negative subjective norms prevailed in the community are also essential to be impacted by this approach.

Although mothers in both groups were at the same and low level of practicing EBF (30-32\%) at baseline, sharp increment was observed in both groups, regardless of the magnitude. However, later at 6 months steady decrement was seen in the intervention group with significant change, while sharp decrement shown in the control groups which ended-up without significant change. This is contrary to what the WHO recommends children under the age of 6 


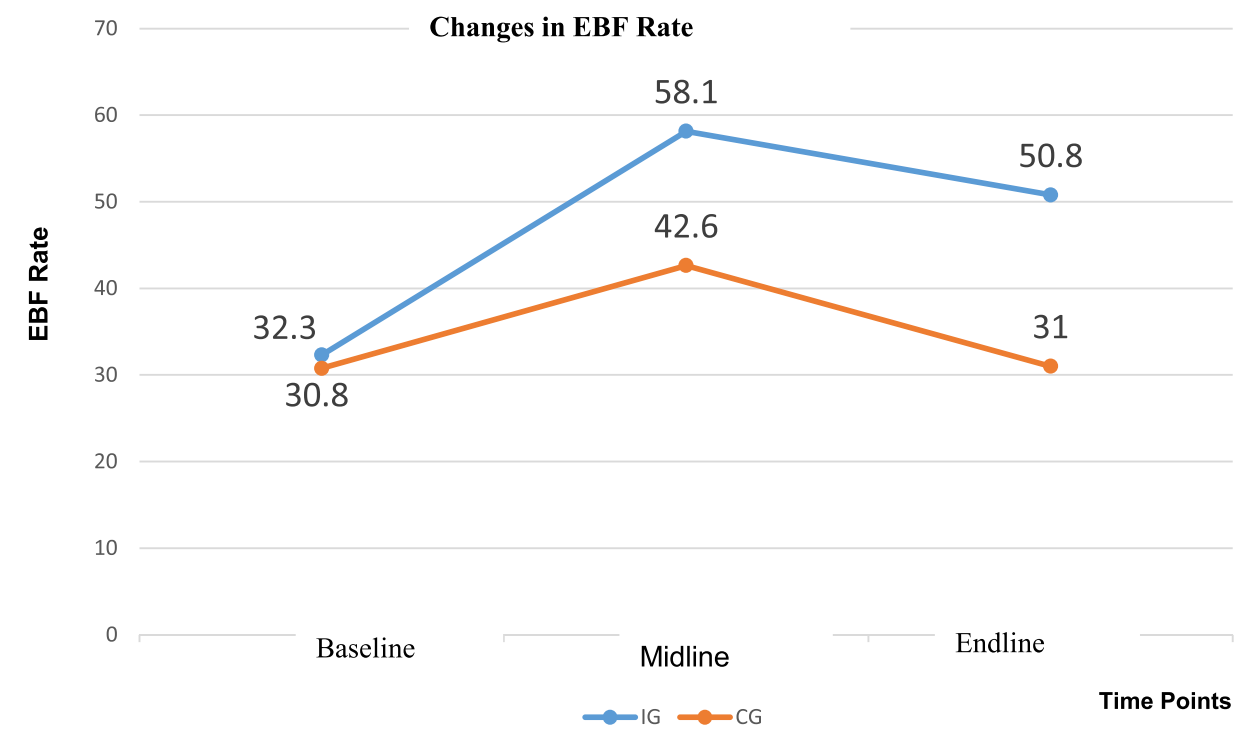

Figure 2 Comparing changes in EBF rate between the two groups, intervention study, Jimma town, 2021.

months should be exclusively BF. In fact, the most recent demographic and health survey (EMDHS 2019) reported that the percentage of EBF decreases sharply with age (from $73 \%$ of infants at $0-1$ month to $68 \%$ at $2-3$ months and further, to $40 \%$ at $4-5$ months). However, the practice of EBF for children till the age of 6 months has increased from $49 \%$ in 2005 to $59 \% .{ }^{25}$ However, our finding showed $58.1 \%$ at third month while $50.8 \%$ at six months.This lower practice of EBF till age of 6 months in our study might be due to the urban study setting while EDHS includes both rural and urban settings. This means EBF is more affected in urban settings such as in the case of Jimma town- $33.3 \%{ }^{30}$ as compared to rural settings $67 \%{ }^{8}$ Besides this justification, our intervention could not achieve the current national proportion of $\mathrm{EBF}$ practice, ${ }^{25}$ and Nigeria-58.8\%. ${ }^{41}$ This difference might be due to the cross-sectional nature of both of the other studies, and the latter was national which included both rural and urban settings. The decline after the midpoint could be prevented if the number of visits increased, probably, planning an additional visit around the fifth month. This recommendation is actually in conflict with the WHO standard number of visits that is only five (two at prenatal and three within 7 days of birth. ${ }^{4,13}$

PDA increased the practice of EBF at 3 and 6 months through engaging and supporting strategies. Social support through active engagement of relevant others can help mothers to improve the practice of EBF. Such social supports are not addressed well in the developing countriesone of the failure of health system responsiveness.
Addressing social needs require social and community support and safety; building environment and health carerelated behavior and improved ideation factor-related gaps. The role of relevant others such as grandmother and/or husband can be used as a form of family support, who were engaged in our intervention by positive deviants to facilitate the practice of BF. Current lifestyle changes the role of a mother to have a dual role as a career woman and a housewife. If parents (mothers and fathers) have a career, the responsibility of caring for baby is mostly given to grandmothers. Hence, the effectiveness of our intervention may not be referred to mothers' only but also considerable contribution of relevant others in the process of implementing PDA matters.

The intervention group showed improvements at midline for key BF practices. Ever BF increased by $11 \%$ in the intervention group compared to the control group (89\%) at follow-up. The mothers in the intervention group who reported BF within 24 hours were almost twice as compared to the counterparts. However, nationally, $6 \%$ of infants under age 6 months were not $\mathrm{BF}$ at all. Hence, this intervention is still effective in improving ever $\mathrm{BF}$ practice. ${ }^{25}$ This finding was supported by an earlier study conducted in Ethiopia ${ }^{42}$ which reported timely initiation of BF. In our case, after initiation, the proportion of mothers in the intervention group who EBF within the last 24 hours, increased from baseline to midline and then decreased to endline. The highest point of EBF among mothers in the intervention group was at midline. This indicates the appropriateness of this community-based 
PDA intervention that improved those BF practices, and prevented decline of EBF after the third month.

On the contrary, there were no significant differences among the groups concerning pre-lacteal feeding practice across the three time points. The pre-lacteal feeding declined in both groups by midline, although the change in percentage decrease in the intervention group was more than twice that of the control group. However, there were significant differences among the two groups on feeding expressed breast milk during their absence at midline and endline. The baseline proportion of this practice is low as compared to other BF practices in both intervention and control groups. The proportion of mothers who expressed breast milk in the intervention group increased overtime, while there were no significant increments in the counterparts. This finding is supported by another study, in which increment of expressing breast milk within 6 hours of delivery was observed. $^{43}$

When we see the indirect measures of BF intensity, the intervention was effective in delaying menses return, decreasing bottle-feeding practices, increasing frequency of BF during the night ( $4-6$ times) and day times (4 -6 times) and increased duration of suckling breast, compared to control groups. From this finding, we can learn that delayed menses return and decreased bottle-feeding practices among intervention group could be due to intensive $\mathrm{BF}$ and exclusiveness. However, the frequency of $\mathrm{BF}$ at day- and nighttimes was inconsistent and imbalanced in terms of the number of practitioners. To declare the frequency of $\mathrm{BF}$ is intensive, the day-time (4 -6 times) and nighttime (4-6 times) feeding should be balanced in terms of proportion of practitioners. The general recommendation of BF frequency per day (8-12 times $)^{1,4}$ is vague and not indicative of $\mathrm{BF}$ intensity. The fact that frequency and duration of $\mathrm{BF}$ are not accurate measure of intensity, ${ }^{36,44,45}$ rather used for estimation and to draw a connection between the effectiveness of PDA in improving EBF practice and its indirect measures. In the beginning, we assumed that if EBF practice improved, other indirect measures should be improved, otherwise, the recall bias would be the major limitation of this study. Generally, those indirect measures are used to estimate till the first 6 months since no significant natural decrement of feeding frequency and duration of suckling expected and since no complementary feeding is recommended. Sometimes, the frequency and duration of suckling are reversely related when the infant gets older and more than 6 months. In support of this, the proportion of infants, by the duration of suckling, increased from weak to strong at midline and endline in the intervention groups compared to control groups, and who were on the medium duration of suckling (expected) increased from baseline to end line.

Although BF is sufficient and beneficial for infant nutrition in the first 6 months of life, and for the health of mother whose knowledge, attitude, and self-efficacy to practice EBF might be necessary but not sufficient conditions. The respective proportions in both groups were decreased from knowledge to attitude and then to selfefficacy at the three time points. This means, those mothers who had good knowledge might not have a favorable attitude and those who have a favorable attitude might not practice $\mathrm{BF}$, which is supported by a study conducted in Nigeria- $76.8 \%$ of knowledge with $40 \%$ of practice. ${ }^{46}$ Unlike the baseline, there were significant differences observed on these ideation factors at midline and endline. The percentage of mothers in the intervention group who had good knowledge, favorable attitude, and good self-efficacy were increased by 20,22 , and 33 points from baseline to endline, while minimal increments in the counterparts. The reason for no change in favorable attitude at control group might be due to the existence of many subjective norms that need planned communitybased intervention, unlike knowledge and self-efficacy, which are prone for change due to minimal practice and receiving information. In addition, mothers who were in the control group might also learn from the repeated measure of this study. Out of the three ideation factors considered in this study, the maximum positive increments were recorded on good self-efficacy followed by a favorable attitude when the time goes forward. This implies that the PDA (counseling and social support) intervention is effective overtime to improve ideation factors. In addition to this, intention to BF (which was almost equal and high at baseline in both groups) might not be sufficient to practice EBF, since no significant change in EBF practice in the control group at the end. In addition, studies on PDA reported that without having proper knowledge and a favorable attitude, feeding practice can be adopted. ${ }^{47}$ However, the earlier view did not work in this study since the reverse happened (change in practice lead to a change in ideation factors) because both ideation factors and practice positively changed. Because, while mothers adopt a certain behavior, she ask why and how and who do that and compatibility with the norm at a time. 
Evidences showed that studies tested the PDA were conducted in rural settings where people may be mostly affected by subjective norms. They want to practice what others did and they progressively try to learn it to improve their knowledge and attitude, ${ }^{18}$ unlike urban women of our study who had exposure to different information and want to verify which one is good to catch and follow, then practice if they believe and understand it.

Although the PD approach had been effectively utilized to address diverse health and social problems in different parts of the world, ${ }^{18-21,48,49}$ but not tested in improving EBF practice in urban settings. The PD approach differs from most of the usual health communication strategies derived from the diffusion of innovations or social marketing theory. Such assumptions assumed the end users as a passive receiver of persuasive information. The PD approach challenges these longlasting understandings, and prefer innovative ideas, which are often existing within the community, so that the role of the change agents is to facilitate a process whereby the community can self-discover these ideas, cocreate messages and prove by themselves to exercise in more sustainable and desirable ways. In this approach, people come to believe that they can adopt a different practice that already prevailing in their community, with some practitioners who are an icon for that specific behavior. Since the required behaviors are already in practice, the solutions can be implemented without delay or waiting for access to outside resources.

Furthermore, our findings are against the premises of PDA that was assumed by the founders. At the beginning, scholars of PDA thought that the assumption of conventional learning theories (knowledge will change attitudes, then attitude change practice) does not work, rather this approach is deeply rooted in changing practice first, then learning may come after that. This means when people change their actions, their knowledge or attitude or both may change later. However, this may not work in every scenario specifically for EBF in urban settings. Our finding challenges this previous concept of PD approach which still needs to be tested in different settings for different behaviors. We can conclude that separately understanding behavior, knowledge, and attitude, and trying to draw unidirectionality is not acceptable. This might be verified by both EBF practices and ideation factors were improved in this study. Probably, the prediction direction between these might be bi-directional. Practically, one special thing added in our study is that PDs were not simply started the visit to share their experience, rather well trained to conduct informational counseling, and actual social support, unlike other studies. ${ }^{18-21,48-50}$ Hence, the PD approach has important implications for researchers and practitioners who are trying to address global nutrition challenges through local community-based solutions. Therefore, the shifting paradigm of the positive deviance approach is still calling researchers to generate additional evidence in a different context.

\section{Limitations and Strengths/Implications of the Study}

Although the effectiveness of PDA was analyzed and discussed, the unintended-desirable and undesirable effects were not documented and reported. Self-report bias, recalling bias and social desirability bias could be considered as limitations especially in measuring the primary outcome variables. To minimize reporting bias, items were prepared to verify each other and indirect measures were used. To minimize recalling bias, the baseline information was limited to the last 5 years for the last child only and the 24hour recall method for some outcomes.

Since it is a randomized trial study, it might be also limited concerning internal and external validity. Internally by; experiences of subjects had between three point measurements may be changed overtime (e.g, knowledge change as a result of pre-intervention interviews), changes in EBF practice as a result of participation in a study, Threats to external validity may arise from differences between target populations and source populations. For example, interaction between selection criteria/process and intervention (participants who fulfilled the criteria for selection may be more or less likely to benefit from an intervention compared to the general population). Interaction between study setting and intervention (participants who knew that they were under study may react differently to the intervention compared to the target population).

However, still we can generalize this finding to urban settings. Masking subjects in such community trial is difficult, even impossible, but we blinded the data collectors. Since the outcome is sensitive to change (rate/proportion), lost to follow-up mothers were included in the subsequent analysis so that the difference between the groups might not be overestimated. For this reason, following the intention-to-treat analysis implies some of the effect size (rates) may be underestimated. The good thing 
was that the rate of lost to follow-up was not more than $2 \%$, which was $(3 / 260 \times 100=1.1 \%)$.

Although the intervention and control group were living in non-adjacent clusters/kebeles, still there might be information contamination since all are living in the same town with narrow buffering zones. To minimize this, cluster randomization takes advantage of individual randomization, which might lead to substantial information contamination. Comparing the last 5 years' baseline information with the current practice of EBF may underestimate or overestimate the change in proportion/rate.

Besides these limitations, the study was strong in terms of retaining mothers throughout the study period, with a minimal percentage (1.2\%) of lost to follow-up from both groups. Our achievement might be due to the appropriate number of subsequent doses/visits provided by the mothers (PDs) to the mothers at their home, unlike the other studies in which the intervention provided at the facility level through health professionals with unjustified a single counseling dose. The other strength is its rigorous scientific design using a cluster randomized control intervention, which included a large sample size and was an integral part of the existing community health system. As far as we know, this study is the first in Ethiopia and Africa that evaluated the effect of PDA intervention on EBF practices under the age of 6 months.

The results of this study may have a meaningful contribution to the existing knowledge regarding community intervention programs and should encourage future research and policymaking. Improved knowledge, attitude and transferable skill from PDs to mothers, the spill-over effect of remained information in the community, and solving the community's problem by, from, and to the community are some of the practical implications and strengths we learned from this study. In addition, this rigorously examined approach will help other researchers to learn procedural and methodological replicability in applying this approach. Measuring implementation outcomes of this intervention and further investigation in different contexts and behavior is recommended using this finding as baseline information. Ethiopia has implemented the urban HEP at the grassroots level since 2009, through household modeling approach in urban settings. Therefore, the existing health system should scale up this strategic approach as an added value. This means, FMOH and Jimma Town Health Office should consider this strategy in increasing coverage of home visit specific for promoting EBF and as a mechanism of future task shifting and reducing loads from UHEPs to PDs.

\section{Conclusion}

The PDA intervention was effective in increasing EBF practice. We recommend the promotion and use of the positive deviance approach as a strategy to improve EBF practice in urban community settings. It was also effective in improving the secondary outcomes such as knowledge, attitude, and self-efficacy toward EBF practices. Based on this finding, scaling up PDA intervention would improve BF practices where by to ensure nutritional adequacy. Moreover, prioritizing PDA intervention at urban settings could have a significant impact on overall child health outcomes in Ethiopia. Applying the PDA has been significantly associated with improved BF and timely initiation of complementary feeding practices. Hence, the health system should explore the adoption of the PD approach as a way of promoting optimal BF. In line with this, adopters should consider interventions focusing on improving maternal ideation factors, which in turn might improve BF practices or the reverse, could happen. This type of intervention should consider designing and funding of community-based promotion of EBF practices to change the state of the art - subjectively and negatively prevailing in discouraging the practice in urban settings.

\section{Abbreviations}

ANC, antenatal care; BCC, behavior change communication; $\mathrm{BF}$, breastfeeding; $\mathrm{C} / \mathrm{S}$, cesarean section; $\mathrm{CHWs}$, community health workers; CI, confidence interval; EBF, exclusive breastfeeding; FGD, focus group discussion; FMoH, Federal Ministry of Health-Ethiopia; GA, gestational age; HAD, Health Development Army; HEP, health extension professionals; HEWs, health extension workers; HP, health post; HPs, health professionals; IDI, in-depth interview; KMC, kangaroo mother care; MDG, Millennium Development Goals; $\mathrm{MOH}$, Ministry of Health; MOH, Ministry of Health; NMR, neonatal mortality rate; $\mathrm{PD}$, positive deviance; PDA, positive deviance approach; PDI, positive deviance inquiry; PDs, positive deviants; PHC, primary health care; PNC, post-natal care; SDG, Sustainable Development Goals; SVD/VD, spontaneous vaginal delivery; U5MR, under 5 years of child mortality rate; UHEPs, urban health extension professionals; UNICEF, The United Nations International Children's Emergency Fund; WHDA, Women Health 
Development Army; WHDALs, Women Health Development Army Leaders; WHO, World Health Organization.

\section{Data Sharing Statement}

The datasets used and/or analyzed during the current study are available from the corresponding author on reasonable request. Supplemental material for some methodological details is submitted along with this main manuscript.

\section{Acknowledgments}

We acknowledge International Institute for Primary Healthcare-Ethiopia (IIFPHC-E) and John Hopkins University-USA for financial and technical support, and follow-up. In addition, thanks to Jimma University (JU) and project finance office of JU, Jimma Town Health Office, UHEPs, study participants, PDs and data collectors.

\section{Disclosure}

The authors have disclosed that they do not have any potential conflicts of interest for this work, financial or otherwise.

\section{References}

1. World Health Organization. Exclusive breastfeeding for optimal growth, development and health of infants. 2019.

2. Khan J, Vesel L, Bahl R, Martines JC. Timing of breast feeding initiation and exclusivity of breastfeeding during the first month of life: effects on neonatal mortality and morbidity-a systematic review and meta-analysis. Matern Child Heal J. 2015;19(4):68-79.

3. World Health Organization. Essential nutrition actions: improving maternal, newborn, infant and young child health and nutrition. Geneva: World Health Organization; 2013.

4. World Health Organization. Guidelines for essential newborn care encompass. 2017.

5. World Health Organization. The optimal duration of exclusive breastfeeding. Report of an expert consultation. Geneva; 2002.

6. Alderman H, Fernald L. The nexus of nutrition and early childhood development (ECD). Annu Rev Nutr. 2017;37(4):47-76. doi:10.1146/ annurev-nutr-071816-064627

7. World Vision Kenya. Baringo Country nutrition survey: disaster risk reduction smart methodology final report. Kenya: World Vision Kenya; 2013.

8. Central Statistical Agency (CSA) [Ethiopia] and ICF International (USA). Ethiopia demographic and health survey 2016: key indicators report: Addis Ababa, Ethiopia, and Rockville, Maryland, USA. CSA and ICF; 2016.

9. Bilal N. Health extension program: an innovative solution to public health challenges of Ethiopia-a case study. Heal Syst. 2012;20 (2012):20.

10. Ethiopia Federal Ministry of Health. Count down 2015. A decade of tracking progress for maternal, newborn and child survival the 2015 report of Ethiopia. 2015.

11. FMOH. Health Sector transformation plan. Addis Ababa, Ethiopia; 2015.
12. Ethiopian Federal Ministry of Health. National strategy for child survival. AddisAbaba, Ethiopia; 2015.

13. Aboubaker S, Qazi S, Wolfheim C, et al. Community health workers: a crucial role in newborn health care and survival. $J$ Glob Health. 2014;4(2):20-30. doi:10.7189/jogh.04.020302

14. Federal Democratic Republic of Ethiopia. Demographic and health survey, MOH, AddisAbaba. 2016.

15. Ministry of Health $(\mathrm{MOH})$ Ethiopia. National policy for maternal infant and young child nutrition. Ethiopia: MOH; 2013.

16. World Health Organization. Integrated management of childhood illness (IMCI) guideline. 1990.

17. Ethiopia Federal Ministry of Health. Urban health extension program implementation manual. Addis Abeba: FMOH; 2013.

18. Zeitlin M, et al. The use of nutritional "positive deviants" to identify approaches for modification of dietary practices. Am J Public Heal. 1976;66(1):38-42. doi:10.2105/AJPH.66.1.38

19. Bolles K, Speraw C, Berggren G, Lafontant JG. Ti Foyer (hearth) community-based nutrition activities informed by the positive deviance approach in Leogane, Haiti: a programmatic description. Food Nutr Bull. 2002;23(4):9-15. doi:10.1177/15648265020234S103

20. Sethi V, Kashyap S, Seth V, Agarwal S. Encouraging appropriate infant feeding practices in slums: a positive deviance approach. Pakistan J Nutr. 2003;2(16):4-6.

21. Marsh DR, Schroeder DG, Dearden KA, et al. The power of positive deviance. BMJ. 2004;329:1177-1179. doi:10.1136/ bmj.329.7475.1177

22. Koetsenruijter J, van Lieshout J, Lionis C, et al. Social support and health in diabetes patients: an observational study in six European countries in an era of austerity. PLoS One. 2015;10(8):13-25. doi:10.1371/journal.pone. 0135079

23. Ethiopia Federal Ministry of Health. Ethiopia's health extension program evaluation study report. 2011.

24. Jimma Town Health Office. Jimma Town health office annual report of 2017; personal communication. 2017.

25. Centeral Statistical Agency FDR of E. Mini demographic and health survey 2019. AddisAbaba: MOH; 2019.

26. WHO/UNICEF. On being in charge - a guide for middle level management in PHC. Geneva. WHO "Health for All" series. WHO Geneva and Alma Ata Declaration, WHO/UNICEF. 1978.

27. Yitayal M, Berhane Y, Worku A, et al. Health extension program factors, frequency of household visits and being model households, improved utilization of basic health services in Ethiopia. BMC Health Serv Res. 2014;14:156. doi:10.1186/1472-6963-14-156

28. Dearden KA, Quan LN, Do M, et al. Work outside the home is the primary barrier to exclusive breastfeeding in rural Viet Nam: insights from mothers who exclusively breastfed and worked. Food Nutr Bull. 2002;23(4):99-106. doi:10.1177/15648265020234S114

29. Tesema A, Sinaga M, Bhattacharjee A, Malik T. Assessment of knowledge, attitude and practice of women towards exclusive breast feeding in Jimma Health Center, Jimma Town, Southwest Ethiopia. J Med Sci Technol. 2017;6(1):47-60.

30. Seifu W, Assefa G, Egata G. Prevalence of exclusive breast feeding and its predictors among infants aged six months in Jimma. $J$ Pediatr Neonatal Care. 2014;1(3):00017.

31. Federal MoH. Family health department of Ethiopia. National strategy on infant and young child feeding. Ethiopia; 2010.

32. Leykum LK, Pugh JA, Lanham HJ, Harmon J, McDaniel RR. Implementation research design: integrating participatory action research into randomized controlled trials. Implement Sci. 2009;4 (1):1-8. doi:10.1186/1748-5908-4-69

33. World Health Organization. Breastfeeding counselling a training course participants â $€^{\mathrm{TM}}$ manual part one sessions 1-9. 2009.

34. Mora A, Russell D, Dungy C, Losch M, Dusdieker L. The Iowa infant feeding attitude scale: analysis of reliability and validity. J Appl Soc Psychol. 1999;29(11):2362-2380. doi:10.1111/j.15591816.1999.tb00115.x 
35. Ismail TA, Sulaiman Z. Reliability and validity of a Malay-version questionnaire assessing knowledge of breast feeding. Malays $J$ Med Sci. 2010;17(3):32-39.

36. Lung'aho MS, Huffman SL, Labbok MH, Sommerfelt E, Baker J. Tool kit for monitoring and evaluating breastfeeding practices and programs demographic and health surveys. USAID/WHO; 2009.

37. Srivastava A, Gwande K, Bhattacharya S, Singh VK. Impact of the positive deviance approach on breastfeeding practices among tribal pregnant women: a before - after intervention study. CHRISMED $J$ Heal Res. 2019;6(4):222. doi:10.4103/cjhr.cjhr_165_18

38. Shakya P, Kunieda MK, Koyama M, et al. Effectiveness of community-based peer support for mothers to improve their breast feeding practices: a systematic review and meta-analysis. PLoS One. 2017;12(5):e0177434. doi:10.1371/journal.pone.0177434

39. McLachlan HL, Forster DA, Amir LH, et al. Supporting breast feeding In Local Communities (SILC) in Victoria, Australia: a cluster randomised controlled trial. BMJ Open. 2016;6(1):82-92. doi:10.1136/bmjopen-2015-008292

40. Dearden K, Altaye M, Maza ID, et al. The impact of mother-tomother support on optimal breast-feeding: a controlled community intervention trial in peri-urban. Revista Panamericana de Salud Pública. 2002;12(3):193-201. doi:10.1590/S1020-498920020 00900008

41. Akadri A, Odelola O. Breast feeding practices among mothers in Southwest Nigeria. Ethiop J Heal Sci. 2017;30(5):697-710.

42. Belachew A. Timely initiation of breastfeeding and associated factors among mothers of infants age 0-6 months old in Bahir Dar City, Northwest, Ethiopia, 2017: a community based cross-sectional study. Int Breastfeed J. 2019;14(1):1-6. doi:10.1186/s13006-018-0196-3
43. Goodchild L, Hussey L, McPhee AJ, et al. Promoting early expression of breast milk in mothers of preterm infants in a neonatal unit: a best practice implementation project. JBI Evidence Synthesis. 2018;16(10):2027-2037.

44. World Health Organization. WHO report in breast feeding practices. 2019.

45. Robert E, Coppieters Y, Swennen B, Dramaix M. Breastfeeding duration: a survival analysis - Data from a regional immunization survey. Biomed Res Int. 2014;2014:1-8. doi:10.1155/2014/529790

46. Oche MO, Umar AS, Ahmed H. Knowledge and practice of exclusive BF among nursing mothers in Kwara state, Nigeria. Afr Health Sci. 2011;11(3):518-523.

47. Kim B, Singhal A, Kreps GL. Health Communication: Strategies for Developing Global Health Programs. Peter Lang Incorporated, International Academic Publishers; 2013:2153.

48. Ghassemi H, Mansour M. Positive Deviance In Child Nutrition: With Emphasis On Psychosocial And Behavioral Aspects And Implications For Development. The United Nations University; 1990.

49. Tuhus-Dubrow R. The power of positive deviants: a promising new tactic for changing communities from the inside. Boston Globe. 2009;29. Available form: https://rebeccatuhusdubrow.net/2009/11/ 29/470/. Accessed August 13,2021

50. Lapping K, Marsh DR, Rosenbaum J, et al. The positive deviance approach: challenges and opportunities for the future. Food Nutr Bull. 2003;23(4):128-135. doi:10.1177/15648265020234S117
Risk Management and Healthcare Policy

\section{Publish your work in this journal}

Risk Management and Healthcare Policy is an international, peerreviewed, open access journal focusing on all aspects of public health, policy, and preventative measures to promote good health and improve morbidity and mortality in the population. The journal welcomes submitted papers covering original research, basic science, clinical \& epidemiological studies, reviews and evaluations, guidelines, expert opinion and commentary, case reports and extended reports. The manuscript management system is completely online and includes a very quick and fair peer-review system, which is all easy to use. Visit http://www.dovepress.com/testimonials.php to read real quotes from published authors. 